\title{
Opinião pública e política externa: insulamento, politização e reforma na produção da política exterior do Brasil
}

\author{
Public opinion and foreign policy: insulation, politicization and \\ reform in the production of Brazilian foreign policy
}

CARLOS AURÉLIO PIMENTA DE FARIA*

Rev. Bras. Polít. Int. 51 (2): 80-97 [2008]

\section{Introdução}

O caráter insulado do processo de produção da política externa brasileira, fortemente centralizado no Itamaraty, tem sido amplamente reconhecido. Há, porém, indícios de alterações importantes nesse padrão tradicional, a partir do início da década de 1990, e pressões crescentes para que tal processo se torne mais permeável às articulaçôes, interesses e demandas de uma diversidade de outros atores, tanto estatais como societários. Uma vez que o padrão top-down de produção da política exterior do Brasil passa a ser questionado de modo mais sistemático, evidencia-se a importância de se analisar a maneira como a opinião pública pode (ou deveria) impactar esse processo, mesmo porque as expectativas e anseios da população do país têm passado a referenciar o debate e o jogo doméstico de interesses acerca das relações internacionais do país. Contudo, ao contrário do que ocorre nos países centrais, são ainda escassos no Brasil os estudos que se dedicam à problemática das interações entre opinião pública e política externa.

O presente ensaio tem como objetivo principal explorar as razóes de tal "negligência", enfatizando a relevância de um tratamento mais sistemático do impacto, empiricamente observado nos países centrais, da opinião pública sobre a política externa. Pretende-se, também, discutir o significado da perspectiva, mais claramente normativa, acerca da necessidade de que, também no âmbito da política exterior, o Estado seja mais responsivo às demandas e interesses da sociedade.

Para tanto, o trabalho está organizado da seguinte maneira: inicialmente, discutem-se os fatores que explicam o caráter insulado do processo de produção da política externa do Brasil. Na segunda seção, são apresentadas as razões e os indicadores de uma mudança, aparentemente em curso, no processo de formação

* Professor da Pontifícia Universidade Católica de Minas Gerais - PUC-Minas e Doutor em Ciência Política pelo Instituto Universitário de Pesquisa do Rio de Janeiro - Iuperj (carlosf@pucminas.br). 
de tal política no país, destacando-se o impacto esperado de algumas reformas institucionais já realizadas ou propostas. A terceira seção discute a evolução dos estudos, principalmente norte-americanos, acerca das interações entre opinião pública e política externa, ressaltando o seu caráter desmistificador, uma vez que, ao contrário do pressuposto realista, das descobertas dos estudos da primeira geração e dos argumentos muitas vezes esgrimidos pelas burocracias públicas e por formuladores da política externa, a opinião pública tem se mostrado, pelo menos nos países centrais, relativamente bem informada acerca das questóes internacionais, apresentando padrões estáveis e percepçôes, valores e prioridades coerentes e racionais. Nas considerações finais, buscamos compreender as razões da periferização dessa discussão no Brasil e explorar o lugar que tal questionamento pode (ou deve) assumir na pauta de pesquisas dos analistas brasileiros de política externa e o seu status esperado na agenda pública do país.

\section{Compreendendo o insulamento do processo de produção da política externa brasileira}

Se hoje parece haver um consenso entre os analistas da política exterior do Brasil (doravante PEB) acerca do caráter insulado do processo de produção de tal política no país, talvez se possa dizer, também, que os fatores e processos que explicam esse insulamento já se encontram mapeados, pelo menos em suas linhas gerais. De maneira sucinta, parece-nos possível afirmar que a tradicional centralização do processo de formação da política externa no Itamaraty pode ser compreendida pela confluência de distintos fatores, quais sejam: (a) o arcabouço constitucional do país, que concede grande autonomia ao executivo em tal seara, relegando o Congresso Nacional a uma posição marginal, o que não é singularidade brasileira (Milner, 1997); (b) o fato de o legislativo brasileiro ter delegado ao executivo a responsabilidade pela formação da política externa; (c) o caráter "imperial" do presidencialismo brasileiro; (d) o fato de o modelo de desenvolvimento por substituição de importações ter gerado uma grande introversão nos processos políticos e econômicos do país, redundando em grande isolamento internacional do Brasil, revertido parcialmente a partir do início dos anos 90; (e) o caráter normalmente não conflitivo e largamente adaptativo da atuação diplomática do país; e, por fim, mas não menos importante, (f) a significativa e precoce profissionalização da corporação diplomática do país, associada ao prestígio de que desfruta o Itamaraty nos âmbitos doméstico e internacional.

Esses fatores, somados, parecem explicar o baixo grau de politização da política externa do país, pelo menos até o final da década de 1980, o que reforça e justifica o insulamento do Itamaraty, que encara a política externa principalmente como uma política de Estado. Ainda que tais fatores tenham sido explorados de maneira relativamente sistemática pelos analistas da PEB, à exceção, eu acredito, do nosso ponto "f", uma vez que, na literatura específica, o Itamaraty ainda 
figura, predominantemente, como uma "caixa preta", considero ser importante desenvolvermos um pouco mais a questão.

No que diz respeito ao arcabouço legal do país, a Constituição Federal de 1988, consolidando a tradição do período republicano, concede grande autonomia ao executivo nacional na formação da política externa. Ainda que alguns autores, como Almeida (1999) e Celli Junior (2003), sugiram que a arquitetura constitucional brasileira busque equilibrar as atribuições do legislativo e do executivo na seara das relações internacionais, a interpretação predominante, principalmente quando comparações internacionais são apresentadas, é a de que o executivo brasileiro desfruta de uma quase hegemonia sobre o processo. Isso porque cabe ao poder legislativo pouco mais que ratificar ou vetar os tratados internacionais ex post facto, além de autorizar o Presidente a declarar guerra e celebrar a paz. Porém, como nos lembra Alcântara, "exemplos de rejeição [de tratados internacionais, por parte do parlamento brasileiro] são raríssimos" (2001, p.15), em função dos elevados custos da não ratificação, em termos de tempo de negociação e de credibilidade internacional. Importa aqui, também, como se discutirá com mais detalhe adiante, recordar que a postura preponderante dos parlamentares brasileiros parece ser a de um certo alheamento em relação às questôes internacionais. Note-se, ainda, que os sistemas presidencialistas de governo tendem a se ancorar em processos decisórios caracteristicamente mais centralizados.

No que concerne à postura do parlamento brasileiro, Lima e Santos, em texto do começo da década, demonstraram que a política externa, e muito particularmente a de comércio exterior, "são objeto natural de delegação de poder decisório do Legislativo para o Executivo", em função de sua sensibilidade às pressões distributivas, do tema requerer elevada expertise e da questão do comércio exterior demandar estabilidade das decisões. Contudo, a "atual configuração institucional do processo decisório da política de comércio exterior caracteriza uma situação mais próxima da abdicação do que da delegação de autoridade" (2001, p. 131). Tal delegação significou, durante o período do desenvolvimento por substituição de importações, ganhos mútuos para executivo e legislativo, uma vez que a política de industrialização protegida atendia aos interesses dos dois poderes. Com a mudança no paradigma de desenvolvimento do país e de seu modelo de inserção internacional, a partir do início da década de 90, o predomínio do executivo nesta área parece ser melhor caracterizado como "abdicação" do legislativo, posto que: (a) o "papel meramente ratificador do Congresso deixa de ser eficiente em uma economia globalizada” (p. 125); (b) que a política tarifária passou a focar não mais o processo de industrialização, mas a superação das crises de balanço de pagamentos e a produção de superávits comerciais para o pagamento do serviço da dívida externa; e (c) que a nova forma de inserção internacional competitiva do país passou a produzir efeitos distributivos diversificados.

Mesmo reconhecendo o predomínio do executivo, Neves discute o "distanciamento aparente do Legislativo" (2006) e sugere, em um outro trabalho, 
relativo às negociações do Mercosul e da Alca, que a participação do poder Legislativo nessa área é mais eficiente do que parece, isto é, o comportamento dos parlamentares no processo decisório de política externa corresponde aos seus interesses. Isto quer dizer que a relação entre os poderes executivo e legislativo na formulação da política externa brasileira de cooperação regional é mais complexa do que a divisão de autoridade presente no texto constitucional pressupóe. (2003, p. 3). Também relativizando as análises tradicionais acerca do suposto padrão de abdicação dos parlamentares brasileiros em matéria de política externa, Alexandre identifica no comportamento de delegação dos congressistas do país o uso de certos mecanismos de controle sobre o Executivo que "lhes permitiriam, em caso de discordância a respeito da delegação, voltar a participar do processo decisório" (2006, p. 89). Os fatores que, atualmente, têm pressionado no sentido da adoção de uma postura mais pro ativa do Congresso brasileiro no campo das relaçoos internacionais serão discutidos na próxima seção.

Outro fator importante para a compreensão do caráter insulado da produção da PEB está relacionado às especificidades do presidencialismo brasileiro. Se o sistema presidencialista de governo está ancorado na divisão de poderes, nos célebres "freios e contrapesos" articulados pelos founding fathers da democracia norte-americana, a concentração de poderes pelo executivo brasileiro tornou habitual a denominação de nosso presidencialismo como "imperial" (Moraes, 2001). Essa concentração é evidenciada pelo controle que o presidente tem sobre a agenda do legislativo, pelo uso abusivo de medidas provisórias e pela possibilidade de reeleição, entre outros fatores. Ainda que a denominação mais corrente nos meios acadêmicos seja hoje a de um "presidencialismo de coalizão", dada a necessidade de que maiorias parlamentares estáveis sejam articuladas pelo executivo nacional, a preponderância do presidente tem sido reiteradamente confirmada (e.g. Figueiredo e Limongi, 1999).

$\mathrm{O}$ padrão insulado de produção da PEB é também resultado da longa vigência no país de um modelo introvertido de desenvolvimento, calcado na busca de substituição de importações. Se o planejamento econômico estatal, o Estadoempresarial, a proteção do mercado interno e a abertura ao capital internacional caracterizaram o bem sucedido modelo de industrialização brasileiro, que entra em crise na década de 1980, o significativo isolamento internacional do país, produzido pelo modelo, acentuando assim tendências históricas e estruturais/ geográficas, parece ter também contribuído para o alheamento dos atores sociais brasileiros em relação à problemática internacional. Mesmo porque o modelo substitutivo de importações, de colorações nacionalistas, contava com amplo respaldo dos setores empresariais e da sociedade em geral.

Cabe recordarmos, também, o impacto do caráter não conflitivo e largamente adaptativo da atuação diplomática do país. Ainda que as oscilações da PEB, ao longo do século XX, no sentido do "americanismo" ou do "globalismo", tenham suscitado controvérsias domésticas, mais acentuadas quando da busca de maior 
autonomia para o país no cenário internacional, o caráter tradicionalmente pragmático da atuação da diplomacia brasileira procurou, via de regra, a consecução dos objetivos em tela pela via negocial e, na medida do possível, através da busca de minimização do caráter eventualmente ideológico das diretrizes propostas. Procurando agir dessa maneira, o Itamaraty buscava restringir o grau de politização da PEB, preservando o que alguns vêem, ainda hoje, como o seu quase monopólio sobre a formação de tal política.

Finalmente, cabe ressaltarmos um elemento essencial para a compreensão do caráter insular da formação da PEB, qual seja: a própria constituição, a forma de atuação do Itamaraty e o prestígio de que desfruta a corporação diplomática brasileira no interior da máquina estatal e na sociedade em geral, bem como no sistema internacional (Barros, 1986; e Cheibub, 1985). De maneira sintética, parece-nos possível atribuir a centralidade ou o predomínio do Itamaraty no processo de produção da PEB também a uma diversidade de fatores associados à própria diplomacia do país, quais sejam: à precoce profissionalização da corporação diplomática brasileira; ao poder de formação autônoma das novas geraçôes de diplomatas, pela via dos cursos do Instituto Rio Branco, fundado em 1945; à evocação constante do "legado do Barão do Rio Branco", chanceler da primeira década do século XX de grande sucesso e popularidade; à coesão dos membros da corporação, resultado tanto de seu processo de formação e de socialização no âmbito do IRB quanto da restrita base social de recrutamento dos diplomatas (Moura, 2007).

Segundo Cheibub (1985), a partir da década de 1960, com a perda de centrali dade dos diplomatas "organizacionistas", ou seja, preocupados com a organização do Itamaraty, e dos "estilistas", preocupados com a "forma" do fazer diplomático, passam a prevalecer no seio da corporação os profissionais "formuladores".

Com o surgimento dos estilos 'formuladores', o Itamaraty entra numa nova fase: após o período de retração, com a 'casa arrumada', pode procurar exercer um papel mais decisivo no cenário nacional. Essa disposição, aliada à força do grupo face a outros grupos de elite, efetivamente confere ao Itamaraty uma influência decisiva na formulação das posiçōes internacionais do Brasil (Cheibub, 1985, p. 129).

Tendo discutido de maneira sucinta os fatores que parecem explicar o caráter insulado da produção da $\mathrm{PEB}$, a próxima seção é dedicada a uma análise, igualmente sintética, das razões e dos indicadores de uma mudança, aparentemente em curso, no processo de formação da política exterior do país.

\section{O desencapsulamento da política externa do Brasil: uma mudança de paradigma?}

Inicialmente, é necessário que se diga que, se hoje são significativos os indícios de uma maior porosidade do processo de produção da PEB, talvez seja precipitado 
afirmar categoricamente ter havido uma mudança de paradigma na formação de tal política, de um processo claramente top down para um formato mais bottom up. Até que reformas institucionais estruturantes não tenham sido implementadas, como, por exemplo, a adoção de um mecanismo de autorização prévia, por parte do legislativo, para negociaçóes internacionais conduzidas pelo executivo, em discussão hoje no Congresso Nacional, não me parece sensato sugerir uma mudança de paradigma. Isso porque os indicadores de mudança discutidos nesta seção do trabalho também podem ser compreendidos como resposta adaptativa do executivo às pressões intra-governamentais, parlamentares, dos governos subnacionais, de grupos de interesse e de organizações da sociedade civil, as quais certamente têm se avolumado ao longo dos últimos anos. Nesse sentido, parece pertinente recordarmos aqui a seguinte máxima, que pode ser pensada como um slogan da corporação diplomática brasileira: "a melhor tradição do Itamaraty é saber renovar-se”. Se esse slogan pode ser interpretado como a versão benigna da adaptabilidade da diplomacia do país, cabe ressaltarmos a crítica de Saraiva acerca do "conservadorismo corporativo do Itamaraty" (2006, p. 452).

O principal fator a pressionar pelo desencapsulamento da produção da PEB é o duplo processo, em curso desde o início dos anos 90, de mudança no modelo de desenvolvimento e no padrão de inserção internacional do país. A superação do modelo substitutivo de importaçōes e a busca de uma inserção internacional competitiva, como demonstrado por Lima (2000), acarretaram uma mudança significativa no impacto redistributivo doméstico da política exterior, gerando uma progressiva politização de tal política, até porque o país intensifica e diversifica sua participação nas instâncias multilaterais e passa a se envolver em uma multiplicidade de negociaçôes internacionais. Concomitantemente, o processo de globalização, de liberalização econômica e a "revolução" nos meios de comunicação têm ampliado o coeficiente de internacionalização da sociedade brasileira.

Cabe destacarmos, também, um dos impactos não esperados do processo de descentralização chancelado pela Constituição de 1988, que ampliou significativamente os graus de autonomia dos governos subnacionais. Esse processo fez com que estados e municípios passassem a defender de maneira mais veemente os seus interesses particulares também no que diz respeito às relações internacionais do país, o que tem incluído a institucionalização de instâncias específicas, no âmbito subnacional, para a viabilização desses interesses e demandas (Vigevani et al, 2004; Saraiva, 2006; Brigagão, 2005; e Pereira, 2004).

Ainda no que diz respeito aos fatores que têm redundado em pressões para a alteração ou flexibilização/oxigenação do processo de produção da $\mathrm{PEB}$, é importante destacarmos o fato de política externa e política doméstica serem hoje, no Brasil, muito mais imbricadas, em função também da mudança nos padrões de impacto doméstico da PEB, que tem gerado custos e benefícios diferentes aos diversos segmentos sociais. No que tange à maior visibilidade doméstica das relações internacionais do país, alguns fatores adicionais devem ser mencionados, 
como, por exemplo, a grande centralidade adquirida pela chamada "diplomacia presidencial" desde a gestão de Cardoso. Ademais, o "institucionalismo da semiperiferia" (Faria, 2007), capitaneado pelo Brasil no âmbito sul-americano, tem gerado, por diversos motivos, grande reverberação doméstica.

Como desdobramento desses processos, verifica-se no país, com inédita intensidade, a mobilização de uma variedade de grupos de pressão e de organizações da sociedade civil no sentido da defesa de seus interesses específicos no que diz respeito à PEB (Carvalho, 2003; Oliveira \& Pfeifer, 2006; Oliveira \& Onuki, 2007; e Santana, 2001).

Toda essa "efervescência internacionalista" do país, que redundou também na grande proliferação dos cursos de relações internacionais no Brasil, ao longo da década passada (Lessa, 2006), fez da política externa questão relevante no debate eleitoral brasileiro, como testemunhado nas eleições presidenciais de 2002 e 2006. Nesse contexto, a política exterior do governo Lula, dita "assertiva" ou "altiva", muito parece ter contribuído também para a ampliação da visibilidade social das estratégias de inserção internacional do país. Isso em função: (a) das controvérsias domésticas que ela tem suscitado (vide a postura, por vezes francamente agressiva, do Partido da Social-Democracia Brasileira, principal agremiação oposicionista); e (b) do fato de o governo Lula, por "medida compensatória” da adoção de uma política macroeconômica ortodoxa, contrária às propostas petistas, sistematicamente recorrer à sua política externa, no plano discursivo e tático, para efeito de afirmação da coerência de sua trajetória política e na busca de apaziguamento de sua base interna de sustentação.

Toda esta mobilização doméstica tem gerado, de um lado, pressões no sentido da reversão do padrão insulado de produção da PEB e, por outro, reações adaptativas da presidência e do Itamaraty. Mesmo que, como já mencionado, reformas estruturais no processo de formação da política externa ainda não tenham sido implementadas no país, cabe destacarmos algumas propostas em discussão e avaliarmos, de maneira tentativa e preliminar, o impacto esperado de algumas alterações institucionais, certamente tópicas, já efetivadas. Antes, porém, parece prudente resgatarmos o seguinte alerta feito por Oliveira e Pfeifer:

As duas décadas de globalização e de redemocratização fizeram que a política externa seja hoje mais transparente e permeável à sociedade brasileira. O relacionamento entre o Estado e os atores sociais mostra-se efetivo e crescente. A dinâmica da participação da sociedade civil varia de acordo com o tema em foco e com o momento político: tende a ser maior em assuntos politicamente sensíveis, tais como as negociações da Área de Livre Comércio das Américas (Alca), e menor em questôes mais específicas. Generalizações são precipitadas e para cada temática da agenda externa é preciso discernir, entre outros aspectos, o grau de institucionalização e a capacidade propositiva de atores não-governamentais, a receptividade da burocracia estatal às demandas da sociedade, a capacidade de 
coordenar interesses divergentes e a variação de padrões de relacionamento de acordo com o estilo de cada administração federal (2006, pp. 389-390).

No que concerne o que denominamos aqui de resposta adaptativa do executivo brasileiro, mais especificamente do Itamaraty, às pressōes para a geração de uma maior porosidade do processo de formação da PEB, parece-nos importante destacar a maneira como se tem tentado, se não atender plenamente, pelo menos abrir caminho para o diálogo com os governos subnacionais e com o empresariado. Como reação à crescente autonomia e insatisfação dos governadores de estado e prefeitos de grandes cidades brasileiras, o Ministério das Relaçōes Exteriores criou, em 1997, a Assessoria de Relaçōes Federativas, que veio a ser designada, a partir de 2003, Assessoria Especial de Assuntos Federativos e Parlamentares. Vale recordar, ainda, que o Itamaraty criou escritórios regionais de representação em diversos estados da Federação.

A chamada "diplomacia federativa" do país tem, formalmente, o objetivo de promover uma maior cooperação entre os entes federados, gerando coordenação nas estratégias internacionais e o compartilhamento de informaçôes e de recursos materiais (Pereira, 2004). Se o intuito subjacente é o de evitar a falta de sintonia e as contradiçóes entre o governo federal, os governadores e prefeitos e os representantes parlamentares, cabe perguntarmos em que medida tais esforços não pretendem também tutelar tais atores, ou pelo menos manter suas iniciativas sob vigilância.

Se a institucionalização, por parte do MRE, de canais para oxigenar as "relações interiores" é sem dúvida uma inovação importante, cujo impacto ainda precisa ser estudado mais detidamente, devemos recordar a seguinte afirmação de Saraiva, para quem, "é verdade que o Brasil tem uma das mais centralizadas formas de ação externa do Estado” (2006, p. 450).

Contudo, reconhecendo as demandas específicas e diversificadas do empresariado nacional, e em resposta à sua crescente mobilização, articulação e ativismo na defesa de seus interesses nas negociações internacionais, notadamente na área do comércio, o Itamaraty tem buscado, nos últimos anos, a ampliação de seus canais de diálogo e consulta. A conformação da Coalizão Empresarial Brasileira, organização supra-setorial do empresariado, criada em 1996 sob a liderança da Confederação Nacional das Indústrias, é fruto da constatação, por parte do setor privado nacional, da necessidade de "libertar-se da tutela do Itamaraty nos Fóruns Empresariais” (Santana, 2001, p. 173). Santana ressalta também a pertinência da "percepção de que o setor empresarial funciona como 'massa de manobra' para os negociadores brasileiros" (Idem, p. 175). Esse autor reconhece a "persistente postura 'autonomista' dos operadores diplomáticos brasileiros, que resistem ao compartilhamento do processo decisório em política externa brasileira" (p. 182). 
Notando que vale aqui a mesma nota de cautela sugerida acima, relativa à incerteza quanto aos objetivos "democratizantes" do MRE, cabe destacarmos, como ilustração do adensamento e institucionalização relativa das interaçóes entre diplomacia e empresariado no Brasil, a criação da Seção Nacional da Alca, em 1996, e do Grupo Interministerial de Trabalho sobre Comércio Internacional de Mercadorias e de Serviços (GICI), em 1999, além do Comitê Empresarial Permanente do MRE, em 1992, do Fórum Consultivo Econômico e Social do Mercosul, em 1996, e da Seção Nacional de Consulta sobre a União Européia, além de diversos conselhos empresariais de cunho bilateral (Carvalho, 2003; Santana, 2001; e Oliveira e Pfeifer, 2006). Porém, já na década de 1970 o Itamaraty havia criado o Departamento de Promoção Comercial, que ilustraria a "bem-sucedida associação entre Estado e empresariado" (Oliveira e Pfeifer, 2006, p.391). São ainda estes últimos autores que, avaliando o governo Lula, afirmam que, "do ponto de vista estrutural e institucional, houve certo arrefecimento na parceria Estado-empresariado" (Idem, p.400). Os autores ressaltam, nas conclusóes de seu trabalho, a persistência de um "modelo anacrônico de relaçôes Estado-sociedade civil em geral e, em particular, empresariado” (Idem, p. 422).

Se tais reformas e processos podem ser vistos como limitados ou como reações tópicas do Executivo, devemos recordar que tramitam no Congresso brasileiro propostas capazes de alterar significativamente o processo de produção da PEB. Cabe destacarmos aqui as propostas de Emenda à Constituição que têm o objetivo de instituir no país um mecanismo de autorização prévia do legislativo para negociação de acordos internacionais, aos moldes da Trade Promotion Authority norte-americana (Alexandre, 2006, e Neves, 2006). O objetivo apregoado é não apenas o de ampliar a responsividade das decisōes na esfera das relaçôes internacionais do país, mas também o de aumentar a legitimidade, a credibilidade e a capacidade de barganha dos negociadores brasileiros. Caso aprovada algum dia, esta polêmica mudança institucional talvez tenha o potencial de fazer do legislativo nacional peça central na formação da PEB, desencapsulando fortemente o processo decisório na matéria e induzindo a articulação dos interesses societários, ainda que ao custo da redução da capacidade de controle dos operadores tradicionais da PEB e da ampliação dos custos domésticos de negociação.

No âmbito específico do Mercosul, processos recentes, como os trâmites para a incorporação da Venezuela como sócio pleno do Bloco e a criação do Parlamento do Mercosul, parecem ter o potencial de ampliar a reverberação doméstica da política externa do país. No primeiro caso, o ruído provocado pelo ativismo da "petrodiplomacia" de Hugo Chávez, por seu anti-americanismo e por seus esforços em ideologizar não apenas a política externa de seu país, mas também as iniciativas de regionalismo na América do Sul, têm redundado em inúmeras polêmicas no âmbito da sociedade brasileira, com ampla cobertura da mídia.

O recém-instalado Parlamento do Mercosul (PM) pretende imprimir uma nova dinâmica ao bloco, propiciando uma melhor capacidade de harmonização 
das legislações nacionais e a mobilização de uma diversidade de atores sociais e políticos, capazes de ampliar a visibilidade e a legitimidade do Mercosul. Com sede em Montevidéu, o PM será composto por dezoito representantes de cada país-membro, eleitos por sufrágio universal, direto e secreto, para um mandato de quatro anos. Nesta primeira legislatura, porém, os Parlamentares do Mercosul foram escolhidos de maneira indireta pelos respectivos congressos nacionais. A primeira eleição direta dos mercodeputados ocorrerá em 2010. Em 2014, eles serão eleitos, de forma simultânea nos Estados-Parte, no "Dia do Mercosul Cidadão", ainda a ser definido. Mesmo que o PM não concretize o "salto supranacional" desejado por muitos, sua criação, paralela à implantação do Fundo de Convergência Estrutural do Mercosul, tem o potencial de conduzir a integração a um novo patamar, ampliando a visibilidade do bloco nas sociedades nacionais e a mobilização dos atores sociais.

Acredito que a discussão precedente tenha evidenciado a progressiva politização da PEB, que parece hoje irreversível. Sendo assim, parece surpreendente o fato de os analistas acadêmicos da PEB devotarem tão pouca atenção ao papel que pode desempenhar a opinião pública no processo de produção da política externa. Na próxima seção, discutiremos, a partir de uma breve apresentação da evolução dos estudos específicos desta subárea, principalmente norte-americanos, as interações entre opinião pública e política externa. Nas considerações finais do trabalho, será esboçada uma explicação para a periferização de tal discussão no Brasil. Será explorado, também, o lugar que tal questionamento pode (ou deve) assumir na pauta de pesquisas dos estudiosos da PEB e o seu status esperado na agenda pública do país.

\section{Opinião pública e política externa}

Desde a massificação das pesquisas de opinião sobre as políticas públicas nos EUA, há aproximadamente sessenta anos, é possível distinguir duas grandes fases nos estudos acerca das interaçōes entre opinião pública e política externa naquele país, quais sejam: uma primeira, que vai do início da década de 1940 ao final da de 1960, na qual a preocupação predominante era sobre o papel que os EUA deveriam ocupar ao fim da Segunda Grande Guerra, assumindo uma postura isolacionista ou um internacionalismo mais atuante, no sentido da preservação de sua liderança no cenário internacional; e uma segunda fase, iniciada na esteira do prolongamento da Guerra do Vietnã, quando se passou a questionar as premissas, descobertas e proposições da análise de opinião pública do período precedente (Holsti, 2001).

Antes de apresentarmos, de maneira necessariamente breve, as principais características, preocupações e descobertas de cada uma destas duas fases, parecenos importante destacar as razões que nos levam a empregar o termo "interações" entre opinião pública e política externa. Com esse termo, sinalizamos o fato, 
talvez óbvio, de que opinião pública e política exterior têm o potencial de se afetar mutuamente. Tal ressalva é importante para que não se imagine que o principal fenômeno em questão seja a possibilidade de que a opinião pública constranja, dite ou ignore o comportamento dos formuladores da política externa, ainda que sejam essas exatamente as questóes que mais pareçam interessar aos analistas.

Aquela primeira geração de pesquisas e de analistas, ainda segundo Holsti (2001), teve como principais protagonistas o cientista político Gabriel Almond, o historiador Thomas Bailey, o jornalista Walter Lippman e o diplomata/ historiador George Kennan. Nas palavras de Holsti, esses autores estiveram entre aqueles que chegaram à seguinte conclusão "lastimável" (mas que é instrumental para os realistas, como demonstrado por Lima, 2000) de que:

The American public, poorly informed about world affairs and indifferent to external events except in times of war or crisis, provides very weak foundations upon which to base the responsible pursuit of vital national interests. Driven by fluctuating moods and lacking any coherent intellectual framework within which to make sense of international events, the public could not be relied on to provide policymakers in Washington with consistent support for an effective international leadership role (Holsti, 2001, pp. vii-viii).

Temia-se, assim, que a opinião pública pudesse se constituir como constrangimento aos tomadores de decisão. Contudo, outras pesquisas mostraram que, quando comparadas aos assuntos domésticos, as atitudes do público norteamericano acerca da política externa tinham muito menos impacto junto aos congressistas. Tais constatações relegaram esta seara de investigação a um plano secundário, até que as controvérsias geradas pela Guerra do Vietnã questionassem "the standard realist prescription for coping with a feckless public: strengthen executive prerogatives in the conduction of foreign affairs" (Idem, p. viii). As pesquisas sobre a opinião pública desta segunda geração passaram a demonstrar que, ao contrário do que se acreditava, a opinião pública não é tão volátil nem tampouco intrínseca e inevitavelmente incoerente, sendo também relevante no processo de produção da política externa. As constatações acerca do baixo grau de informação do público norte-americano sobre a política externa, contudo, jamais foram plenamente refutadas. Porém, estudos têm demonstrado que, mesmo fracamente informado, o público consegue produzir juízos coerentes sobre as questôes internacionais, em um processo que já foi denominado "racionalidade da baixa informação" (Popkin, 1991).

No que diz respeito ao impacto da opinião pública sobre a política externa, contudo, a literatura mais recente está longe de ser conclusiva. Dois importantes estudos publicados nos últimos anos, por exemplo, sinalizaram em direções aparentemente opostas. Richard Sobel (2001), em seu The impact of public opinion on U.S. foreign policy since Vietnam, mesclando análise de pesquisas de opinião a entrevistas com formuladores e operadores da política externa norte-americana, 
mostrou que: (a) "generally, opinion influenced policy, though policymakers also affected opinion, particularly through the media"; (b) "that the major effects of public opinion typically manifest themselves in constraint rather than in policy setting" (p. 234); e (c) que o papel exercido pela opinião pública parece estar crescendo.

Page e Bouton (2006), por seu turno, em The foreign policy disconnect. What Americans want from our leaders but don't get, refutam também, empiricamente, aquela concepção segundo a qual a opinião pública norte-americana sobre a política externa seria ignorante, emocional, vacilante e perigosa para a coerência do processo de produção da política pública. Contrariamente, eles mostram que a "collective opinion is not in fact flimsy, disorganized, or vacillating; it is generally coherent and consistent and, allowing for reasonable adjustments to world events, tends to stay steady over time" (p. ix). É também apresentada farta evidência empírica de que a maior parte dos norte-americanos deseja uma política externa que "places a high priority on economic and social security at home and justice abroad, not just security from attack. Moreover, most Americans favor cooperative, multilateral foreign policies - peaceful, when possible - rather than unilateral military ones" (idem). Constatando que, freqüentemente, a política externa do país diverge fortemente dos desejos da população, os autores sugerem a existência de uma "desconexão" entre os tomadores de decisões e os cidadãos, o que seria não apenas problemático para a democracia, mas também teria impacto negativo sobre a própria qualidade e sustentabilidade da política externa.

Uma vez que esta segunda geração de pesquisas acerca das interações entre opinião pública e política externa vive hoje um período de grande vigor, até porque em toda a parte as fronteiras entre o doméstico e o internacional têm se diluído, outras novas e interessantes constatações têm sido feitas, como, por exemplo: a de que características pessoais e sociais dos indivíduos normalmente não impactam o seu posicionamento acerca da política externa (Page e Bouton, 2006); a de que "a influência da opinião pública varia em democracias diferentes, e que essa influência, na medida em que está relacionada à preocupação dos políticos com a sua reeleição, é mediada pela natureza das instituições eleitorais vigentes em cada democracia" (Chan e Safran, 2006, p. 153); e, entre muitas outras, a de que "the policy impact of public opinion does not depend so much on the specific issues involved or on the particular pattern of public attitudes as on the domestic structure and the coalition-building processes in the respective country" (Risse-Kappen, 1991, p. 479-480).

\section{Considerações finais}

Mesmo persistindo dúvidas acerca da magnitude e das formas do impacto da opinião pública sobre a política externa, o que vale inclusive no caso de iniciativas internacionais altamente polêmicas, acredito ser importante explorarmos as razões da escassez de pesquisas sobre a temática no Brasil. Nestas considerações finais 
abordaremos a questão, de forma reconhecidamente tentativa. Antes, porém, parece necessário apresentarmos um mapeamento dos estudos já realizados no país acerca das interações entre opinião pública e política externa.

Primeiramente, cabe destacar que a grande maioria das investigações sobre a questão no Brasil foi produzida a partir dos esforços de uma única instituição, qual seja, o Núcleo de Pesquisa em Relações Internacionais, da USP. Aqui devem ser mencionadas as seguintes pesquisas: "A Alca na visão das elites brasileiras" (2003); "As estratégias das empresas nacionais e multinacionais no Brasil sobre os processos de integração regional" (2002); "As percepções da elite e opinião pública sobre a política externa brasileira" (1998-2000); "As percepçōes das elites dos países do Cone Sul a respeito da política externa brasileira" (19971999); e "Agendas e estratégias empresariais num contexto de globalização" (1997-1998) (apud Holzhacker, 2006, nota 9, p. 16-17). Como resultado dessas pesquisas, foram publicados os seguintes trabalhos: Oliveira e Albuquerque (2005), que coligem dez estudos dedicados a analisar a PEB "na visão de seus protagonistas"; Albuquerque et al. (1999), que discutem as "percepções das elites do Cone Sul sobre as relaçōes internacionais do Brasil"; Albuquerque e Balbachevsky (1998), que estudam o Brasil e o Mercosul a partir da "percepção dos atores sociais"; Albuquerque, Balbachevsky e Holzhacker (1999), que estão interessados nos "impactos da crise financeira sobre a opinião pública brasileira". Cabe destacarmos, também, a dissertação de mestrado e a tese de doutorado de Holzhacker (respectivamente 2001 e 2006), defendidas no Departamento de Ciência Política da USP. Na primeira, a autora analisa "as orientações e atitudes da população em geral e a influência dos fatores domésticos na construção de um sistema de crenças da opinião pública brasileira". A tese é dedicada a "investigar, de forma comparativa, as diferenças e semelhanças entre as percepções e orientações da elite e da opinião pública de massa a respeito da política externa brasileira" na década de 1990.

Vale ressaltarmos, ainda, que o foco preferencial das pesquisas existentes se concentra, via de regra, nas percepções, valores e preferências das elites brasileiras, com exceção, apenas, de alguns dos trabalhos realizados pelo NUPRI, listados acima. Os demais estudos na subárea têm foco nas elites, como é o caso de: Lima e Cheibub (1996), que estão preocupados com a visão da elite brasileira acerca da democracia, tendo o estudo incluído questionamentos acerca da integração econômica; Souza (2002), que identifica as prioridades da agenda internacional do país e discute a representação de interesses da sociedade brasileira na formação da PEB a partir de pesquisa junto a 149 "personalidades que formam a comunidade brasileira de política externa”; e Manzur (1999), que, de uma perspectiva historiográfica, busca aferir a maneira como uma opinião pública vagamente definida é acionada para justificar o posicionamento dos tomadores de decisão em política externa do país. Cabe destacarmos, por fim, que o Latinobarômetro (http://www.latinobarometro.org), cuja sede fica em Santiago 
do Chile, tem realizado pesquisas de opinião pública, em âmbito regional, normalmente incluindo o Brasil, relativas, entre outras questôes, à integração econômica e aos acordos comerciais. Tais pesquisas, contudo, normalmente têm muito pouca visibilidade no Brasil.

$\mathrm{Se}$ as interações entre opinião pública e política externa têm, como argumentamos, despertado um interesse apenas periférico entre a comunidade acadêmica das relaçôes internacionais do Brasil, parece ser possível sugerirmos que o mesmo acontece no que diz respeito à agenda de pesquisas dos especialistas brasileiros em opiniāo pública. Tal constatação é derivada da escassez de trabalhos com esse foco publicados no periódico Opinião Pública, editado pelo Centro de Estudos de Opinião Pública, da UNICAMP. Editado ininterruptamente desde 1993, o referido periódico publicou, até 2007, apenas dois artigos que tratam da correlação entre política externa e opiniāo pública, quais sejam: "Apoio popular à integração econômica regional na América Latina", de Mitchell A. Seligson (Vol. VI, No. 2, 2000), e "América Latina: política externa e opinião pública", de Frederick C. Turner (Vol. III, No. 1, 1995). Vale destacarmos que ambos os autores são cientistas políticos norte-americanos.

Apresentado este breve levantamento, certamente não exaustivo, mas que parece sustentar a nossa afirmação acerca do caráter periférico de tais questões na agenda de pesquisas dos analistas brasileiros da política externa, passemos, agora, à nossa tentativa de compreender a baixa centralidade dessa temática no Brasil, que parece explicada: (a) por fatores relacionados ao próprio processo de formação da política e ao tipo de impacto produzido pela PEB; e (b) por fatores relacionados à estrutura de incentivos e constrangimentos a pautar, no país, as pesquisas acadêmicas na subárea da análise de política externa.

No que diz respeito ao primeiro grupo de fatores, em larga medida discutidos nas duas primeiras seções deste trabalho, deve-se ressaltar o fato de apenas no início da década passada a política externa do país ter iniciado um processo mais consistente de "internalização", ao mesmo tempo conseqüência e causa de sua crescente politização. Neste contexto, a falta de preocupação mais sistemática com a opinião pública pode ser atribuída não apenas ao caráter precariamente público da diplomacia brasileira, mas também, possivelmente, a uma ainda baixa demanda da sociedade brasileira por maior accountability e responsividade dos agentes estatais nessa área. Parece possível sugerirmos ainda, parafraseando Lima e Santos (2001), a persistência no país de uma "delegação societária" da produção da PEB ao Itamaraty, delegação essa que, na medida em que a globalização amplia os graus de constrangimento sobre a economia brasileira e que as relações internacionais do país passam a impactar diferentemente a sociedade, estaria se convertendo em abdicação.

Por outro lado, são diversificados os fatores relacionados à própria maneira como se conforma no Brasil a subárea da análise de política externa e, também, o próprio campo das relaçôes internacionais, que convergem no sentido de produzir 
o fenômeno que nos cabe aqui compreender. Inicialmente, devemos recordar a própria insipiência das relaçôes internacionais como campo de estudos acadêmicos no país e o fato de a análise de política externa, enquanto subárea, desprestigiada internacionalmente entre meados dos anos 70 e o fim da década de 1980, ter hoje uma institucionalização ainda frágil no Brasil, a despeito das evidências recentes de que tal quadro tende a ser rapidamente superado. Ademais, a forte ênfase historiográfica dos estudos sobre a política externa no país (Almeida, 1999) também pode ser pensada como elemento que contribui para a pouca atenção conferida às interaçôes entre opinião pública e política exterior. Adicione-se o fato de, por ser área acadêmica de constituição relativamente recente, as relações internacionais terem inicialmente privilegiado em seu enfoque aquilo que lhe seria peculiar: o sistema internacional assimétrico e a interação entre os Estados em um contexto de anarquia. Note-se, também, a prevalência da(s) vertente(s) realista(s), a qual relega a um plano secundário o impacto dos fatores internos aos Estados. Apenas recentemente a agenda de pesquisas passou a incorporar, de maneira mais sistemática, a preocupação com os fatores domésticos na produção do comportamento internacional dos Estados. No caso específico do Brasil, devese destacar, ainda, a fraca tradição quantitativista na grande área das ciências sociais (Soares, 2005), à qual se soma o custo relativamente alto das pesquisas de opinião nacionais, lastreadas em amostras representativas.

Por fim, devemos explicitar, ainda que brevemente, as razóes que sustentam a nossa proposição acerca da necessidade de uma maior preocupação com a opinião pública no âmbito das investigações sobre a política exterior do país. Tais razões, uma vez mais, são tanto de ordem analítica quanto normativa. No que diz respeito às motivaçôes propriamente analíticas, cabe destacarmos a importância de se aferir, também por intermédio das pesquisas de opinião, o supostamente crescente grau de internalização ou de politização da PEB. Ademais, parece-nos relevante verificar o grau de respaldo de que desfrutam, no âmbito societário, os grupos de pressão do país, cada vez mais mobilizados na defesa de seus interesses relativos à inserção internacional do Brasil. Bases de dados capazes de distinguir as diferenças nas percepções, valores e preferências dos distintos segmentos da sociedade brasileira, com sensibilidade para as variações territoriais e passíveis de comparação temporal, teriam grande significado não apenas para o trabalho acadêmico, tendo também importância na definição das táticas e estratégias dos distintos atores envolvidos na produção da PEB.

Quanto às motivações de ordem normativa, parece-nos possível afirmar que os estudos sobre a opinião pública têm o potencial de produzir não apenas novas informações, mas também maior accountability e responsividade por parte dos formuladores e operadores da política externa do país, o que redundaria em maior legitimidade, credibilidade e poder de barganha para o Brasil. Seria possível, assim, detectar eventuais desconexões entre opinião pública e política externa, aos moldes daquelas descobertas e denunciadas por Page e Bouton (2006) no caso 
norte-americano, e também oferecer subsídios para que tais desconexões sejam superadas. Afinal, como sugerem esses autores, a falta de respaldo público para a política externa pode "send bad signals to international adversaries, constrain policy choices, upset policy continuity, and destabilize political leadership" (p. 201). Em última instância, o que está em jogo é a própria qualidade do regime democrático do país.

Recebido em 18 de dezembro de 2007 Aprovado em 6 de junho de 2008

\section{Referências bibliográficas:}

ALBUQUERQUE, J.A.G. et al. (1999). Percepções das elites do Cone Sul sobre as relações internacionais do Brasil. Texto para Discussão, No. 693, Brasília, IPEA.

ALBUQUERQUE, J.A.G. \& BALBACHEVSKY, E. (1998). O Brasil e o Mercosul: agenda e percepção dos atores sociais. In: ALBUQUERQUE, J.A.G. (Org.). Alca: aspectos históricos, jurídicos e sociais. Vol.1, São Paulo, FTD.

ALBUQUERQUE, J.A.G.; BALBACHEVSKY, E. \& HOLZHACKER, D. (1999). Os impactos da crise financeira sobre a opinião pública brasileira. Revista Brasileira de Comércio Exterior, No.58, Ano XIII.

ALEXANDRE, C.V.M. (2006). O Congresso brasileiro e a politica externa (1985-2005). Dissertação de Mestrado. PPGRI/PUC-Rio.

ALCANTARA, Lúcio (2001). Os parlamentos e as relações internacionais. Rev. bras. polít. int., Brasília, v. 44, n. 1, 2001. Disponível em: <http://www.scielo.br/scielo.php?script=sci_ arttext\&pid=S0034-73292001000100002\&lng=\&nrm=iso >. Acesso em: 022008.

ALMEIDA, P.R. (1999). O Estudo das Relaçôes Internacionais do Brasil. São Paulo, Unimarco Editora.

BARROS, A.S.C. (1986). A formulação e implementação da política externa brasileira: o Itamaraty e os novos atores. In: MUÑOZ, H. \& TULCHIN, J. (Eds.). A América Latina e a Política Mundial. São Paulo, Convívio, p. 29-42.

BRIGAGÃO, C. (2005). Relaçôes internacionais federativas no Brasil. Rio de Janeiro, Gramma.

CARVALHO, M.I.V. (2003). Estruturas domésticas e grupos de interesse: a formação da posição brasileira para Seattle. Contexto Internacional, Vol. 25, No. 2, p. 363-401.

CELLI JUNIOR, U. (2003). A Constituição, o Parlamento e a política externa brasileira. Publicado em Correio Internacional. [http://www.relnet.com.br/pgn/colunaaj164.lasso]. Disponibilidade: 01/10/2003.

CHAN, S. \& SAFRAN, W. (2006). Public opinion as a constraint against war: democracies' responses to Operation Iraqi Freedom. Foreign Policy Analysis, No. 2, p. 137-156.

CHEIBUB, Z.B. (1985). Diplomacia e construção institucional: o Itamaraty em uma perspectiva histórica. Dados, Vol. 28, No. 1. 
FARIA, C.A.P. (2007). A política sul-americana do Brasil: razões e percalços do 'institucionalismo da semiperiferia'. Análise de Conjuntura, No. 4, abril 2007, 10p. OPSA/ IUPERJ.

FIGUEIREDO, A.C. \& LIMONGI, F. (1999). Executivo e Legislativo na nova ordem constitucional. Rio de Janeiro, FGV.

HOLSTI, O.R. (2001). Foreword. In: SOBEL, Richard. The impact of public opinion on US foreign policy since Vietnam. Oxford, Oxford University Press, pp. vii-ix.

HOLZHACKER, D.O. (2006). Atitudes e percepções das elites e da população sobre a política externa brasileira nos anos 90. Tese de Doutorado, USP, FFLCH, DCP.

HOLZHACKER, D.O. (2001). As atitudes e opiniōes da população a respeito das relações externas do Brasil. Dissertação de mestrado, USP, FFLCH, DCP.

LESSA, A.C. (2006). A intensificação do debate acadêmico e social sobre relações internacionais e política exterior no Brasil. In: ALTEMANI, H. \& LESSA, A.C. (Orgs.). Relaçôes internacionais do Brasil: temas e agendas. São Paulo, Saraiva, p. 457-491.

LIMA, M.R.S. \& SANTOS, F. (2001). O Congresso e a política de comércio exterior. Lua Nova, No. 52, p. 121-150.

LIMA, M.R.S. \& CHEIBUB, Z. (1996). Instituições e valores. As dimensões da democracia na visão da elite brasileira. Revista Brasileira de Ciências Sociais, No. 31, Ano. 11, p. 83-110.

LIMA, M.R.S. (2000). Instituiçōes democráticas e política exterior. Contexto Internacional, Vol. 22, No. 2, p. 265-304.

MANZUR, T.M.P.G. (1999). Opinião pública e política externa do Brasil do Império a João Goulart: Um balanço historiográfico. Revista Brasileira de Política Internacional, Vol. 42, No. 1, p. 30-61.

MILNER, H. (1997). Interests, institutions and information: domestic politics and international relations. Princeton, Princeton University Press.

MORAES, F. (2001). Executivo e Legislativo no Brasil pós-Constituinte. São Paulo em Perspectiva, Vol. 15, No. 4.

MOURA, C.P. (2007). O Instituto Rio Branco e a diplomacia brasileira: um estudo de carreira e socialização. Rio de Janeiro, FGV.

NEVES, J.A.C. (2003). O papel do legislativo nas negociações do Mercosul e da Alca. Cena Internacional, Ano 5, No. 3.

NEVES, J.A.C. (2006). O Congresso Nacional e a política externa brasileira. In: ALTEMANI, H. \& LESSA, A.C. (Orgs.). Relaçôes internacionais do Brasil: temas e agendas. São Paulo, Saraiva, p. 365-388.

OLIVEIRA, A.J. de \& PFEIFER, A. (2006). O empresariado e a política exterior do Brasil. In: ALTEMANI, H. \& LESSA, A.C. (Orgs.). Relaçôes internacionais do Brasil: temas e agendas. São Paulo, Saraiva, p. 389-428.

OLIVEIRA, A.J. \& ONUKI, J. (2007). Grupos de interesse e a política comercial brasileira: a atuação na arena legislativa. IUPERJ/OPSA/NECON, Papéis Legislativos, No. 8.

OLIVEIRA, H.A. \& ALBUQUERQUE, J.A.G. (Eds.)(2005). A política externa brasileira na visão dos seus protagonistas. RJ, Lúmen Júris. 
PAGE, B. \& BOUTON, M.M. (2006). The foreing policy disconnect. What Americans want from our leaders but don't get. Chicago, University of Chicago Press.

PEREIRA, J.A.L. (2004). O federalismo na diplomacia brasileira: o interesse do Itamaraty nas ações externas de governos subnacionais. Cena Internacional, Vol. 6, No. 2, p. 144-159.

POPKIN, S.L. (1991). The reasoning voter. Chicago, University of Chicago Press.

RISSE-KAPPEN, T. (1991). Public opinion, domestic structure, and foreign policy in liberal democracies. World Politics, Vol. 43, p. 479-512.

SANTANA, H.R.P. (2001). Grupos de interesse e a política externa brasileira para a ALCA. Contexto Internacional, Vol. 23, No. 1, p. 167-196.

SARAIVA, J.F.S. (2006). Federalismo e relaçôes internacionais do Brasil. In: ALTEMANI, H. \& LESSA, A.C. (Orgs.). Relações internacionais do Brasil: temas e agendas. São Paulo, Saraiva, p.429-456.

SOARES, G.A.D. (2005). O calcanhar metodológico da ciência política no Brasil. Sociologia, Problemas e Práticas, No. 48, p. 27-52.

SOBEL, R. (2001). The impact of public opinion on US foreign policy since Vietnam. Oxford, Oxford University Press.

VIGEVANI, T. et al. (Orgs)(2004). A dimensão subnacional e as relações internacionais. SP, EDUSC.

\section{Resumo}

Partindo de uma discussão acerca do tradicional insulamento do processo de formação da política externa brasileira, no artigo se discute o impacto potencial das interações entre opinião pública e política exterior, procurando compreender a periferização de tal problemática na agenda de pesquisas dos analistas da política externa do país.

\section{Abstract}

Departing from a discussion about the traditionally insulated process of foreign policy formation in Brazil, the article discusses the potential impact of the interactions between public opinion and foreign policy, trying to understand the marginal role such a question plays in the research agenda of Brazilian foreign policy analysts.

Palavras-chave: Política Externa Brasileira; Opinião Pública; Itamaraty; Processo Decisório

Key words: Brazilian Foreign Policy; Public Opinion; Itamaraty; Decision Making 